\title{
Design and Development of Grip for Circular Test Piece Inuniversal Tensile Testing Machine
}

\author{
Ojo Jeremiah Akinribide, Adetunji Kolawole Ogunkoya, Itopa Monday Momoh, \\ Olasupo Daniel Ogundare, Ba’aku Emmanuel AttahDaniel, Samuel Olugbenga Oloruntoba Olusunle \\ Engineering Materials Development Institute, Akure, Nigeria \\ Email: akinribideojo@yahoo.com
}

Received October 5, 2013; revised November 8, 2013; accepted November 20, 2013

Copyright (C) 2013 Ojo Jeremiah Akinribide et al. This is an open access article distributed under the Creative Commons Attribution License, which permits unrestricted use, distribution, and reproduction in any medium, provided the original work is properly cited.

\begin{abstract}
The design and development of jaw grip for circular tensile test samples in a universal mechanical tester were undertaken in this work. In developing economies, the cost of acquiring laboratory testing equipment and accessories is huge, thereby depriving most of the supposedly advanced laboratories of most of this necessary research equipment. Where the equipment is available, they are either non-functional due to inadequate maintenance know-how or non-availability of necessary accessories. The developed grip in this work is part of an effort at providing accessories as their need arises. Advanced design and manufacturing tools were deployed to develop the jaw grip by using austenitic stainless steel. The developed jaw grip was used on the test equipment to conduct tensile tests on steel samples and the results were found to conform to international standard. Consequently, replacement of worn-out accessories has been carried out in resent time, which eventually saves idle time of equipment or otherwise importation for replacement.
\end{abstract}

Keywords: Mechanical Testing; Tensile Test; Jaw; Grip

\section{Introduction}

The strength of a material under tension has long been regarded as one of the most important characteristics required for design, production, quality control and life prediction (ASTM E8-24T, 1924). Many materials, when in service, are subjected to both internal and external forces/loads that could affect the material directly or indirectly, and examples include the aluminum alloy from which an airplane wing is constructed and the steel in an automobile axle. In such situations, it is necessary to know the characteristics of the material and to design the member from which it is made in order to minimize or avoid any resulting excessive deformation and sudden fracture that could occur [1]. The mechanical behavior of a material reflects the relationship between its response to an applied load or force(s). Some of the required important mechanical properties are strength (yield and ultimate), hardness, ductility, and stiffness [2].

The mechanical properties of a material are related to its behavior when subjected to continuously increasing elongations up to rupture/fracture [3,4]. A thorough understanding of a material's mechanical properties is required by engineers if catastrophic failures are to be avoided. Ac- cording to Aegerter and associates [5], the tensile test is a common standard test and is a valuable method of determining important mechanical properties of engineering materials. The procedural details of the test vary for different material types, but tensile tests are generally conducted at room temperature and relatively slow loading rates.

The mechanical properties of materials are ascertained by performing carefully designed laboratory experiments that replicate as nearly as possible the service conditions. Factors to be considered include the nature of the applied load and its duration, as well as the environmental conditions. It is possible for the load to be tensile, compressive, or shear, and its magnitude may be constant with time, or it may fluctuate continuously [6]. Application time may be only a fraction of a second, or it may extend over a period of many years. Service temperature may be an important factor (depending on the area of application). Mechanical properties are of concern to a variety of parties (e.g., producers and consumers of materials, research organizations, and government agencies) that have differing interests. Consequently, it is imperative that there is some consistencies in the manner in which tests are conducted, and in the interpretation of their results. This 
consistency is accomplished by using standardized testing techniques established and published by international professional bodies. In several practical cases, the ultimate ductile fracture strain determined with tensile test is accepted as a material plasticity measure [7]. In this case, the plasticity has to be defined as an ability of a material to accommodate high permanent strains until fracture appears where this strain reaches certain value called ultimate fracture strain. The strain value until fracture depends not only on the material type, but also on other several factors, as: strain speed, strain history, material starting structure, temperature, specimen geometry, etc. It is impossible to account for all factors in a single mathematical description, due to a complexity of phenomena and an insufficient state of the art, mainly for phenomena present during a plastic strain. Several experiments according to Bao and Wierzbicki [8], have demonstrated that the material fracture process strongly depends on the hydrostatic stress.

In Tensile Testing, the test specimen is deformed, usually until complete rupture or fracture occurs, with a gradually applied increasing tensile load that is applied uniaxially along the longitudinal axis of the specimen (metals and non-metals) which could be circular, rectangular with dimensions in accordance to internationally acceptable standards (ASTM or BS). During testing, deformation is confined to the narrow center region which has a uniform cross section along its length. The test specimen is clamped together in the machine with the aid of upper and lower jaws that has grip ability designed to firmly hold the test specimen. This work is focused at design and producing alternative jaws grip that could perform the same function meeting the required international standard of material characterization by evaluating the tensile properties of a material.

\section{Materials and Method}

\subsection{Basic Development}

The aim of this work is to design and develop jaw grips for circular test piece which is an accessory commonly used in commercially available universal mechanical testing machine. The equipment accessory designed was developed at minimum possible cost without compromising the expected efficiency. The designed components were modeled and analyzed using parametric 3-D design software-Pro Engineer and machined using stateof-the-art advanced manufacturing equipment which include, power Hacksaw, lathe, Computer Numerical Control (CNC) vertical Machining Center and surface grinding machine.

Considering the expected uniform distribution in the applied forces on the test specimen [8], a professional Engineering (Pro-E) software was used to design and model the jaws (upper and lower) as shown in Figure 1. Each

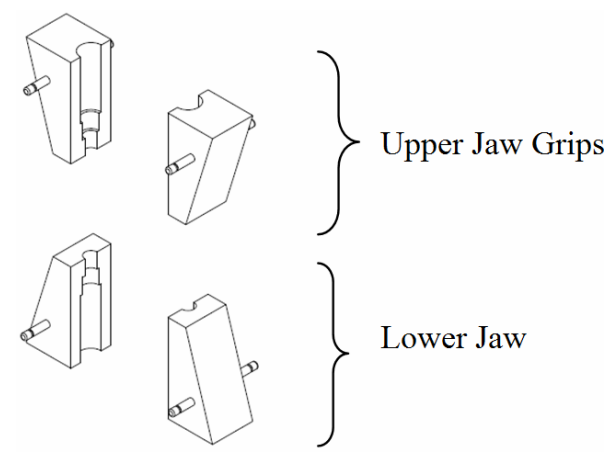

Figure 1. Model of the two pairs of the jaw grip required for tensile test operation.

jaw is designed to have two stage stoppers on the specimen [9]; this is to avoid the likelihood of stress concentration at the end/edge of the gauge length of the specimen. The maximum load of the machine used in this investigation is $50 \mathrm{KN}$. To this effect, a suitable material (Austenitic Stainless Steel) that could withstand the load required-maximum of $30 \mathrm{KN}$ to pull conventionally heattreated metallic materials to failure was selected, this is as a result of its high strength, high resistance to oxidation and its availability. The selected material was subsequently cut with the aid of power Hacksaw to a specific configuration, drilled using drill bits and bored to conform to the designed profile so as to ensure firm grip on any specimen machined to its accepted configuration.

\subsection{Results and Discussion}

The model of the computer aided design of the jaw grips are presented in the figures below:

Figure 2 shows the intricate parts of the designed jaw grip. The jaw was designed and produced to have two stage stopping points (first and second steps), the second stopper is to further reduce or eliminate the possible stress concentration at the end of the gauge length that could have ensued if it is just one. Stress concentration at a particular point of a material is a disadvantage that leads to unexpected premature fracture or deformation in the specimen. In the type of tensile testing machine targeted for this design, the pins are required to hold the grips at the designated position firmly thus enabling rigidity during operation, for this reason, the pins were incorporated in the design and developed as shown in Figure 1 with their corresponding groove through which they are being held firmly to the machine frame. As shown in Figures 2 and 3(a), two pairs of grip are needed to conduct any tensile test. Each of this pair consists of two grips forming the upper and the lower jaw grips. The newly produced jaws grips were subjected to test on a Tensile Testing Machine [as shown in Figure 3(a)] following the predetermined mounting setup shown in Figure 3(b) to conduct several tensile tests on a circular 


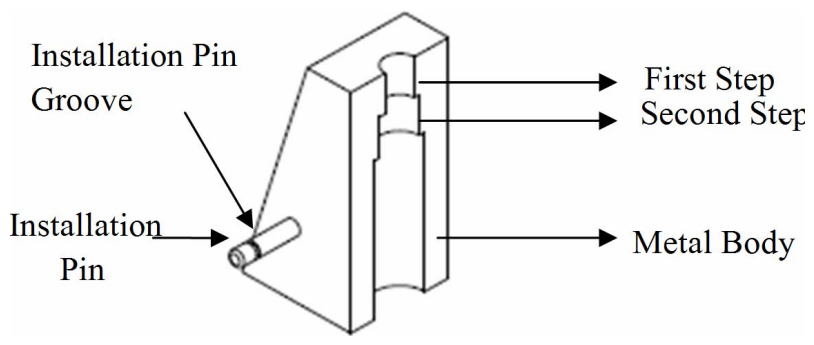

Figure 2. Model showing the intricate part of a piece of the jaw grip.

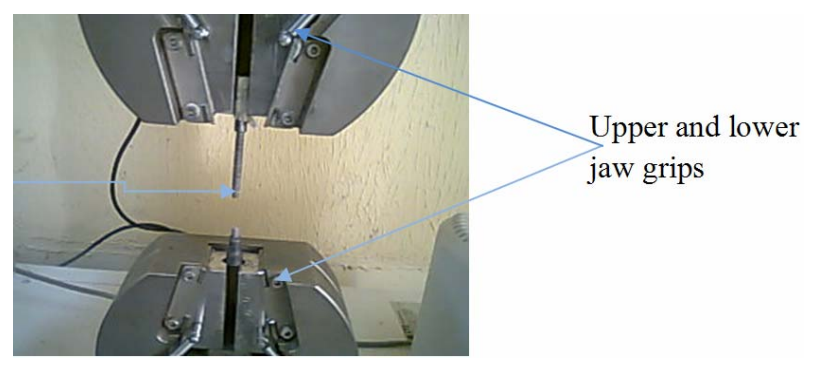

(a)

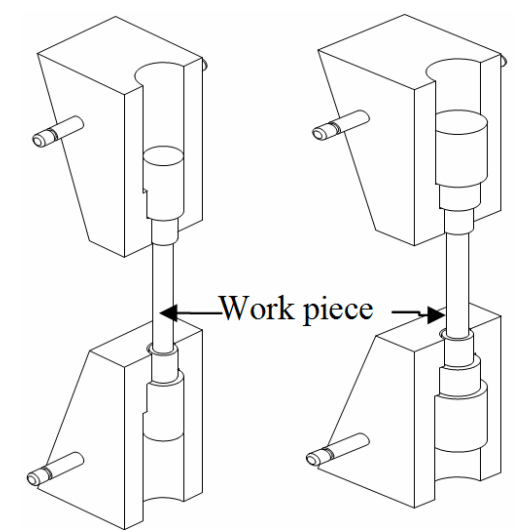

(b)

Figure 3. (a) Tensile circular test piece inside the developed jaw grips on a mechanical tester during performance evaluation (b) Models showing the mounting arrangements of both 1-step and 2-step test pieces on the developed upper and lower jaw Grips.

specimen (mild steel) in accordance with ASTM A352/A 352M-03 and the results were found to conform to international standard (ASTM E8M3) as presented in Table 1.

The grip portion of the circular test piece applicable to the designed and developed jaw grips could be of different configurations but with the same gauge length dimensions as required by international standard. The tensile test results presented in Table 1 shows that 2-step test piece sample yielded the best result in conformity with international standard and this is further confirmed by its simulated performance presenting the best structural stability in Figure 4; Its graph conform with theoretical expectation (ASTM E8M3), in comparison with others presented in Figures 5 and 6. The 2-step grip configuration is the test piece that best match the grip cavity in the developed jaw grip; therefore, the developed jaw grip exhibits reliable performance and therefore serves as a good replacement to the defected one.

Figures 4-6 show typical stress-strain curves obtained in uniaxial tensile tests on mild steel. In these three graphs, the detail explanation of the stress-strain curve is as follows: in Figures $\mathbf{4}$ and $\mathbf{6}$, there is a straight line or linear relationship between stress and strain from origin until it attains a stress level of $250 \mathrm{MPa}$ which is otherwise known as the proportional limit. Thereafter, the stress/strain relationship became nonlinear up to a point $300 \mathrm{MPa}$ which is very near to proportional limit. At 300 $\mathrm{MPa}$, the deformations are largely elastic and on unloading, the specimen regains the original dimensions. But beyond the point $300 \mathrm{MPa}$, the metal yields and suffers plastic deformation. This is indicated by a sudden bend in the curve. Most of the strain after this point is plastic strain which is not recovered on unloading. The value of stress at $300 \mathrm{MPa}$ is called upper yield strength. With further increase in strain, the stress falls a bit to a lower level at 285 MPA. This is due to formation of Lüder bands or slip band otherwise known as the bands in the metal where permanent, plastic deformation begins. With increase in tension, localized plastic flow takes place in a narrow band with boundary planes inclined at a certain angle with the axis of test specimen. However, due to strain hardening of the material in the band, the load again increases till another Lüder band appears in the test piece. This goes on till the whole specimen is full of Lüder bands. Thus between the points $0.07 \mathrm{~mm} / \mathrm{mm}$ and $0.09 \mathrm{~mm} / \mathrm{mm}$ of the tensile strain level the stress is oscillating between two narrow limits. This occurs in alloys having interstitial solid solution structure. The stress at $285 \mathrm{MPa}$ is called lower yield strength.

However with further increase in tensile strain beyond the point $0.09 \mathrm{~mm} / \mathrm{mm}$, when the test piece is full of Lüder bands, the load or stress again starts increasing. The distinction between the two yields may disappear with strain hardening and only a small kink may remain on the stress strain curve. Some author like Zhongchun Chen et al., prefer to take stress value at $285 \mathrm{MPa}$ as the flow stress at the yield point, however, the data given in material standards generally refer to upper yield point. After the $0.09 \mathrm{~mm} / \mathrm{mm}$ the stress-strain curve moves upwards, however, with further deformation, its slope gradually decreases at $450 \mathrm{MPa}$ which is the highest point on the curve. After 450 MPA, the curve goes down. Before the $450 \mathrm{MPA}$, it was observed that increase in strain increases the load on the specimen due to strain hardening [10]. Even after the point 450 MPA, the strain hardening is still there but at some point the area of cross 
Table 1. Results of tensile test performed by the developed jaw grip on different test piece configuration.

\begin{tabular}{ccccc}
\hline \multirow{2}{*}{ Tensile Test Results } & $\begin{array}{c}\text { Yield Strength (Y.S) N/mm } \\
\text { or Mpa }\end{array}$ & $\begin{array}{c}\text { Ultimate Tensile Strength (UTS) } \\
\text { N/mm } \text { or Mpa. }^{2}\end{array}$ & $\begin{array}{c}\text { Elongation } \\
\text { (\%) }\end{array}$ \\
\hline \multirow{2}{*}{ Obtainable (International Standard) } & 275 & $485-655$ & 22 \\
\multirow{2}{*}{ Obtained } & Old grip (Conventional) & 268 & 491 & 21 \\
& 1-step grip & 261 & 425 & 18 \\
\hline
\end{tabular}
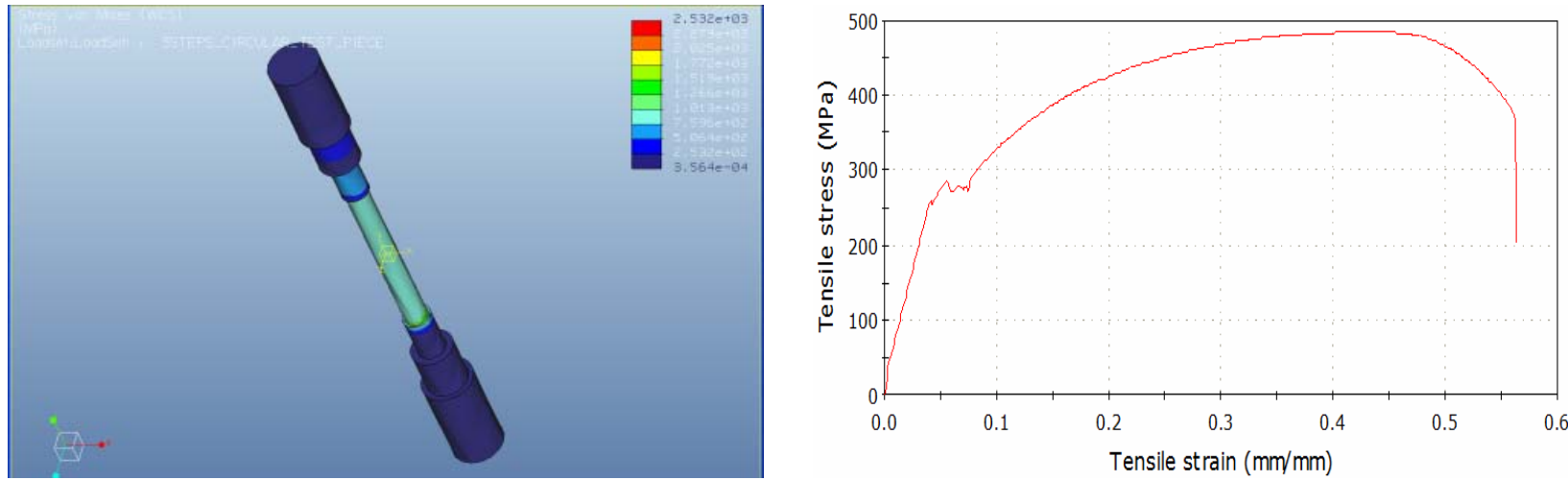

Figures 4. 2-step configuration of grip region, its corresponding simulated behaviour under tensile load and graph of tensile test conducted on it.
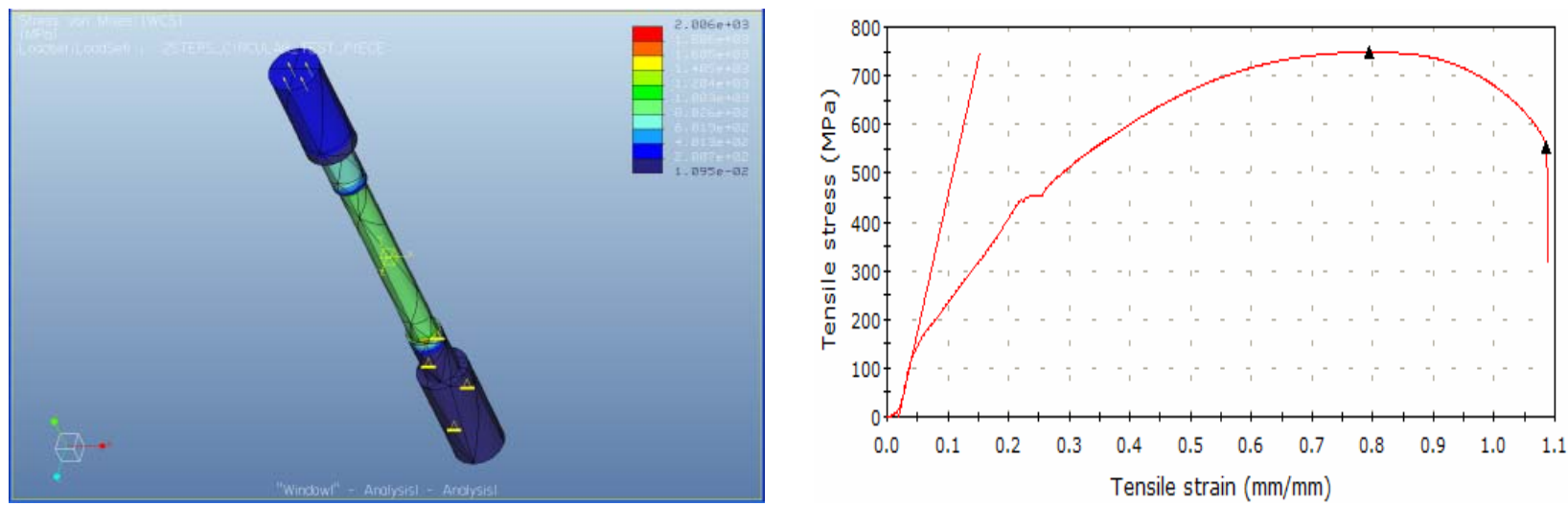

Figures 5. Old-step configuration of grip region, its corresponding simulated behaviour under tensile load and graph of tensile test conducted on it.
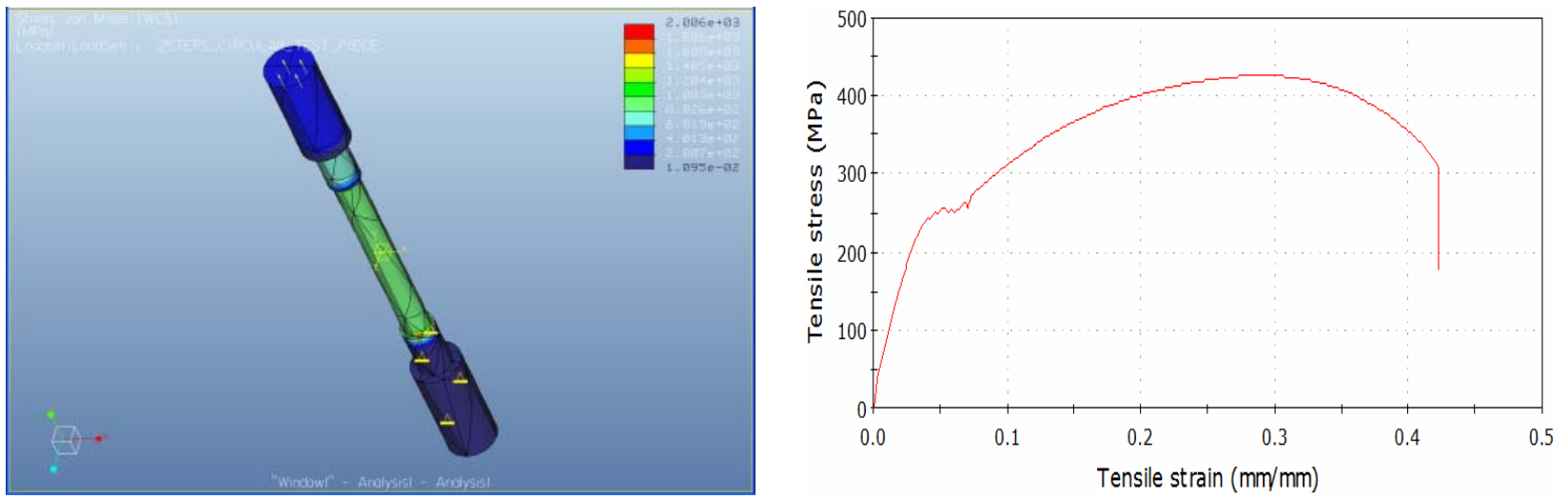

Figures 6. 1-step configuration of grip region, its corresponding simulated behaviour under tensile load and graph of tensile test conducted on it. 
section of the test piece starts decreasing much faster and a neck formation starts, with the result, the force that the test piece can bear decreases continuously with further deformation resulting in an unstable condition. After some elongation in the neck, the specimen fractures at the point $350 \mathrm{MPa}$ at the stress level. Since we have defined stress as force divided by original area of cross section the stress value thus calculated also decreases after $450 \mathrm{MPa}$, however, if we take true stress, as explained below, it will be much higher. The stress at the $450 \mathrm{MPa}$ is known as ultimate tensile strength. At 450 MPa the actual area of cross section is smaller than the original area of cross-section.

\section{Conclusion}

In this work, the design and development of jaw grip for circular tensile test were undertaken. Professional Engineering (Pro-E) software was used in the design and analysis, in the course of doing this, several laws were considered in relation to stress distribution in a specimen under tensile test. Suitable material (austenitic stainless steel) was thereafter selected and machined to a desired and designed configuration. The product was subsequently used to conduct a tensile test on a steel sample and the results were found to conform to an international standard. Due to the availability and accessibility of the raw material used and needed ingenuity, the product thus serves as an excellent alternative to the jaw grips that come with the imported machine. Thus far, the work has brought to focus on a new design and manufactured stepwise grip for circular uniaxial tensile test to serve as an alternative to the usual multi-jaws grip designed for the test.

\section{REFERENCES}

[1] ASTM E8M3 Standard Test Method for Tension Testing of Metallic Materials, 2009.

[2] D. Mohr and S. Henn, "Calibration of Stress-Triaxiality Dependent Crack Formation Criteria: A New Hybrid Experimental-Numerical Method,” Experimental Mechanics, Vol. 47, No. 6, 2007, pp. 805-820. http://dx.doi.org/10.1007/s11340-007-9039-7

[3] Engineer ${ }^{\circledR}$ Wildfire $^{\mathrm{TM}}$ 5.0, “Help Center,” Parametric Technology Corporation, Needham, 2009.

[4] H. Czichos, T. Saito and L. Smith, "Springer Handbook of Materials Measurement Methods,” Springer-Verlag, New York, 2006, pp. 302-307. http://dx.doi.org/10.1007/978-3-540-30300-8

[5] Granta (Materials Intelligence) CES 2007 EduPack, “Getting Started with CSE EduPack,” Granta Design Limited, Cambridge, 2007.

[6] J. Aegerter and H. Bloching, "Tensile Test on Materials According to EN 10002-1 (Issue December 2001)," 11th Trade Fair for Testing Technology, ZwickHausmesse, October 2002, pp. 167-188.

[7] J. Aegerter and H. Bloching, "Probenformen- und Herstellungfür die Prüfungmetallischer Werkstoffe-Schwerpunkt Zugversuch (Specimen Geometries and Specimen Preparation for Testing Metallic Materials, Especially Tensile Test)," 12th Trade Fair for Testing Technology, ZwickHausmesse, October 2003, pp. 50-62.

[8] W. Eyassu and T. Henry, "Mechanical Testing (Tensile Testing),” Louisiana State University, 2009. http://imechanica.org/node/1070StandardE8M.TensileTes tingofMetallicMaterials.ASTM

[9] Y. Bao and T. Wierzbicki, "On Fracture Locus in the Equivalent Strain and Stress Triaxiality Space,” International Journal of Mechanical Sciences, Vol. 46, No. 1, 2004, pp. 81-98. http://dx.doi.org/10.1016/j.ijmecsci.2004.02.006

[10] Z. C. Chen, et al., "Bauschinger Effect and Multi-Axial Yield Behavior of StressReversed Mild Steel,” Metallurgical and Materials Transactions A, Vol. 30A, 1999, pp. 3069-3078. 